\title{
Experimental research of the operation of self-sufficient desalination setup of vapor-air type
}

\author{
P. S. Sokolov ${ }^{1}, A . V$. Bannikov $^{2}$ and $M . V$. Kozlova $^{2, *}$ \\ ${ }^{1}$ Ltd. "KUB", Ivanovo, Russia \\ ${ }^{2}$ Ivanovo State Power University, Ivanovo, Russia
}

\begin{abstract}
The growing global shortage of freshwater resources can be partially offset by the desalination of mineralized ocean and marine waters. The most common methods of desalination today are distillation, based on phase transformations of water, and reverse-osmosis, which consists in passing sea water through semipermeable membranes. The distillation method of desalination is characterized by significant thermal energy needs. In the process of desalination by the reverse-osmotic method, there is a need for the periodic replacement of expensive membranes, the creation of high pressure, which leads to significant energy consumption. In this regard, the actual problem is the study of vapor-air desalination method, based on the law of equilibrium state of vapor-gas-liquid mixtures. The efficiency of devices based on the vapor-air method is a significant increase in productivity due to the additional generation of steam, which reduces the energy costs for heating water in the installation. The purpose of this work is to determine the main factors affecting the performance of the vapor-air type installations. As a result of an experimental study of the operation of aself-sufficient steam-type desalination setup, it was found out that the initial water and air temperatures in the bubbling zone have a key impact on the performance. The high energy efficiency of devices implementing this method, with the quality of the condensate that complies with regulatory requirements, makes the vapor-air desalination method very future-oriented.
\end{abstract}

\section{Introduction}

One of the pressing problems of our time is the shortage of fresh drinking water, due to the uneven distribution of fresh water resources. In the modern world, fresh water is no longer a self-renewing resource. It has become a commercial product, like oil or gas, the degree of availability and availability, which determines the economic and social state of the population or individual countries and regions $[1,2]$.

In most cases, it is possible to overcome the water deficit by desalinating saline waters. This problem has been successfully solved by many countries. According to the International Desalination Association, there are currently about 17,000 setups in 120 countries. This method of obtaining drinking water has become the most widespread in the countries of the Arabian Peninsula, primarily Saudi Arabia, the United Arab Emirates, Kuwait, as well as Spain, the USA and China [3].

Currently, the main methods of obtaining fresh water are distillation and reverse-osmosis.

The distillation desalination method is based on the phase transformations of water and allows getting the finished product, purified from dissimilar impurities, without exerting a chemical effect on it [4]. In distillation setups the amount of heat energy comparable to heat of vaporization is delivered to the water that gets desalinated, then from distillate vapor heat energy is removed for its condensation. One of the major drawbacks of this method is the high power consumption. In addition, such desalination setups are bulky and of low efficiency $[5,6]$.

Obtaining fresh water by the reverse osmosis method consists in passing water through semipermeable membranes that do not conduct salts dissolved in water through themselves, dividing the initial solution into permeate and retentate (concentrate) [7]. This method is effective for desalination of waters with low and medium salinity; it is practically not used in countries with high ambient temperatures (more than $32{ }^{\circ} \mathrm{C}$ ), since in this case membrane hydrolysis process is more intensive, which shortens the period of their operation.

One of the most promising methods of desalination due to its energy efficiency is the vapor-air method based on the law of equilibrium state of vapor-gas-liquid mixtures. In connection with the above mentioned, the problem of vapor-air desalination is extremely important.

\section{Description of the experimental setup}

An experimental study was carried out on a selfsufficient desalination setup [8].

A self-sufficient steam-type desalination setup is a two-compartment tank with a source of thermal energy for a salt water preheater in the form of a solar collector

* Corresponding author: vafdanil@yandex.ru 
with a heat carrier having a normal boiling point higher than the normal saline boiling point, a bubbler, a condenser and a conservator.

A general view of the experimental setup and its schematic diagram are shown in Figures 1 and 2.

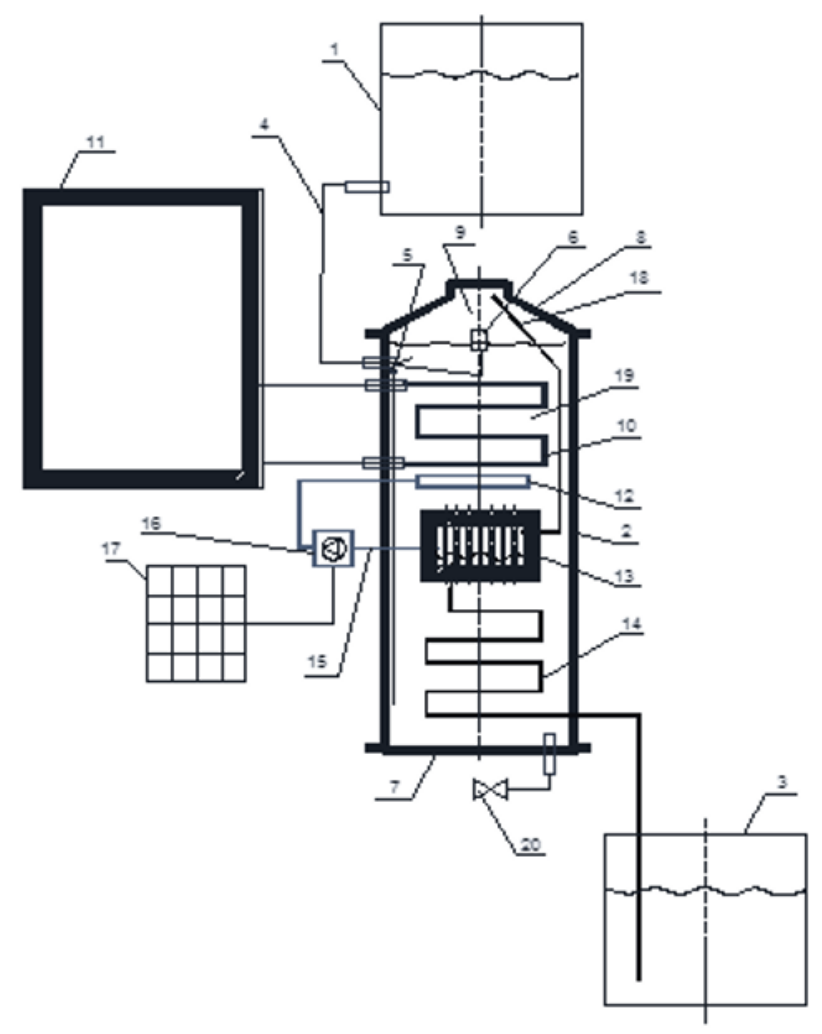

Fig. 1. Schematic diagram of the self-sufficientdesalination setup: 1 - desalinated water tank; 2 - evaporation chamber; 3 capacity-collection of fresh water; 4 - overflow pipe; 5 - valve; 6 - water level sensor; 7 - removable bottom; 8 - removable cover; 9 - zone vapor mixture; 10 - heating element; 11 - solar collector; 12 - bubbling device; 13 - condenser-separator; 14 coil; 15 - pipe; 16 - air blower; 17 - solar battery; 18 - vapor-air mixture tube; 19 - heating zone; 20 - brine drain valve.

The experimental installation includes a desalinated water tank, which is a plastic tank with a volume of 1.5 $\mathrm{m}^{3}$, which is installed above the evaporation chamber and provides the source seawater to the lower part.

The body of the evaporation chamber is made in the form of an aluminum cylinder with an internal diameter of $350 \mathrm{~mm}$ and a height of $2 \mathrm{~m}$ with a wall thickness of 3 $\mathrm{mm}$, the chamber lid is a truncated cone with a height of $300 \mathrm{~mm}$.

The inlet for the overflow pipe is located in the upper part of the evaporation chamber, and the outlet in the lower part. The evaporating chamber is a cylinder with a removable bottom and a removable lid, their fastening by the receiving section is carried out by means of a flange connection. The inner surface of the cover and the water level form an area of vapor-air mixture.

The heating element, made in the form of a copper coil with a diameter of $18 \mathrm{~mm}$ and a length of $3.2 \mathrm{~m}$, is installed in the upper part of the evaporation chamber below the level of desalinated water. The heat carrier circulating in the heating element is heated on the basis of a solar collector, with an area of sun-absorbing surface of $4.4 \mathrm{~m}^{2}$, and the circulation of the coolant in the "solar collector - heating element" circuit occurs naturally.

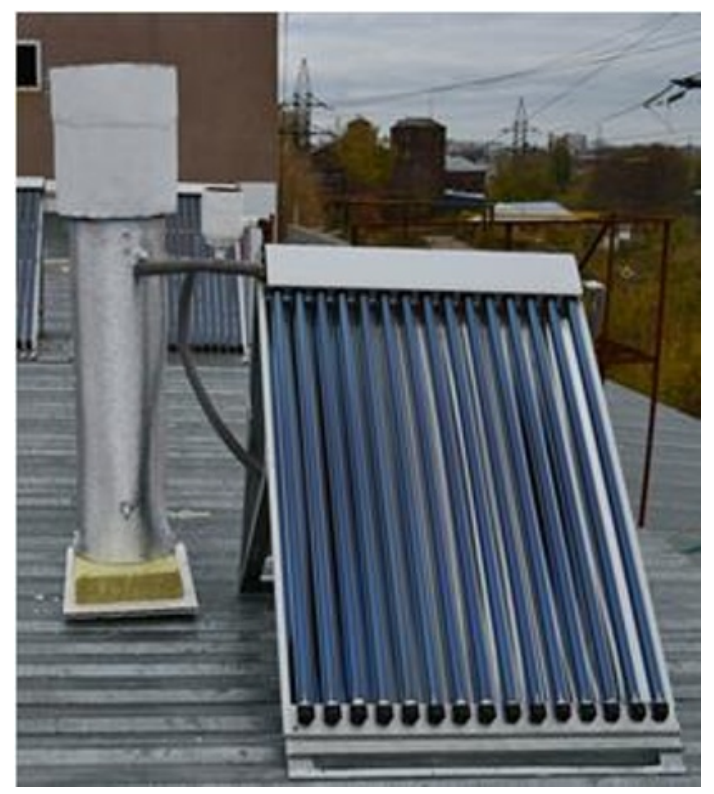

Fig. 2. General view of a pilot self-sufficient desalination setup of sea-water vapor-type.

Under the heating element is placed a bubbling device, which is a flat spiral from a pipe with a diameter of $18 \mathrm{~mm}$ and a length of $1900 \mathrm{~mm}$ with holes with a diameter of $2 \mathrm{~mm}$ located on the water level side with a step of $10 \mathrm{~mm}$.

A condenser-separator is installed under the bubbling device. It is an aluminum shell-and-tube heat exchanger with a heat exchange surface of $1.2 \mathrm{~m}^{2}$. The condenserseparator is connected by a coil with a fresh-water collection container and with an air blower, which communicates with a bubbling device, as well as a steam-air mixture pipe with a vapor-air mixture zone.

The air blower with a capacity of $60 \mathrm{~W}$ and a capacity of $400 \mathrm{~m}^{3} / \mathrm{s}$ is powered by a solar battery, which is a panel of photocells with a capacity of $60 \mathrm{~W}$.

The fresh water receiving tank is made of a plastic volume of $1.5 \mathrm{~m}^{3}$ and is connected to a separator condenser through a fresh water coil with a diameter of $16 \mathrm{~mm}$ and a length of $5000 \mathrm{~mm}$.

\section{The functional principle of the self- sufficient desalination setup}

The air-vapor type desalination setup operates as follows. Desalinated water from the tank of the original sea water through the supply pipe enters the lower part of the installation case. At the location of the heating element and above it, due to the supply of thermal energy from the solar collector, a region of heated sea salt water is formed. Unsaturated air is pumped through a bubbling device through a layer of heated water and in the process of bubbling it is saturated with moisture, 
forming an area of vapor-air mixture above the water level.

Next, the vapor-air mixture enters the condenserseparator, where in the process of heat exchange with salt water it gets dried: condensate through a freshwater coil enters the receiving tank of fresh water, and unsaturated air into the suction path of the air blower. In this case, as a result of heat exchange in the condenserseparator and the freshwater coil with salt water, the heat of condensation is utilized and the desalinated water is cooled. Water with high salinity from the zone above the bubbling device due to greater density falls to the bottom of the installation body, forming a brine zone, from where it merges. Since the initial sea water has a lower density than brine, it will naturally flow into the heating zone, additionally heated due to the perception of thermal energy from the condenser-separator and fresh water coil.

When the water level drops, the sensor opens the valve and the original sea water from the source sea water tank enters the lower part of the installation body through the supply pipe.

For complete autonomy of this installation, a panel of photovoltaic cells is provided, which ensures the operation of the air blower.

\section{The essence of the vapor-air desalination method}

The steam-air desalination method is based on the equilibrium state of vapor-gas-liquid mixtures and is implemented in the installation in accordance with the following cycle: initially air masses with low moisture content enter the supercharger, where they heat up, and their pressure increases, while their moisture content remains unchanged, and relative humidity decreases [9]. After the supercharger, the air is sent to a bubbling device, through the openings of which it is passed through a layer of heated water and is saturated with moisture. The resulting vapor-air mixture, which is characterized by high moisture content, enters the condenser-separator, in which as a result of heat exchange with desalinated water, it is dried and with low moisture content is sent to the blower, and the resulting condensate is in the receiving tank of fresh water.

When air and hot water interact, diffusion, molar transfer of heat and mass, radiant heat exchange, thermal diffusion and non-isothermal mass diffusivity simultaneously occur, all these elementary processes influence each other, and their intensity is determined by the initial conditions of the process and the design features of the installation.

At low temperatures of the air bubbled flow, the thermodynamic equilibrium temperature of the liquid is lower than the saturation temperature under the same pressure; as a result, this difference in the thermal state of the liquid is used to further generate desalinated water vapor. In turn, the supply of heat in the bubbling zone contributes to the saturation of the air flow with moisture. The bubbling of air into the heated water layer intensifies the processes of heat and mass transfer between gaseous and liquid media $[10,11]$. This phenomenon is due to the development of the interaction surface, which has arisen due to the high dispersion of bubbles fed into the liquid. And since the bubble lifting speed is quite high, this leads to turbulence in the flow. Improving the efficiency is also achieved due to the complete utilization of the heat of condensation of the vapor-air mixture in the condenser-separator and cooling of the condensate in the freshwater coil.

Thermal energy for the evaporation of water comes from two sources: the liquid itself and the bubbling air if its temperature exceeds the temperature of the water [12].

The theoretical concepts underlying the process of interaction of the air flow with hot water are described by dependencies (1), (2), (3) [13]:

$$
d=622 \cdot \frac{P_{n}}{B-P_{n}},
$$

where $d$ is the moisture content of $g$ per kg of dry air; $P_{n}$ is the partial pressure of steam, $\mathrm{Pa}$; $\mathrm{B}$ is the total pressure of the vapor-air mixture, $\mathrm{Pa}$;

Since the partial pressure of steam in air is an unambiguous function of moisture content $d$ (dependence 1), the amount of water evaporating as a result of contact with air can be determined by equation (2) [14]:

$$
d W=\beta_{d} \cdot d F \cdot \frac{d_{n}-d_{e}}{1000}
$$

where $\beta_{d}$ is the moisture transfer coefficient, referred to the difference in moisture content, $\mathrm{kg} /\left(\mathrm{m}^{2} \cdot \mathrm{c} \cdot(\mathrm{g} / \mathrm{kg})\right)$; $d_{n}$ is the moisture content of air in the boundary layer of a liquid at its surface temperature, $\mathrm{g} / \mathrm{kgd}$. a; $d_{e}$ is the moisture content of air in the environment, $\mathrm{g} / \mathrm{kgd}$. a ; dF is the elementary platform of moisture exchange, $\mathrm{m}^{2}$;

$$
I=t+0,001 \cdot d \cdot(2493+1,97 \cdot t),
$$

where $I$ is the enthalpy of saturated air, $\mathrm{kJ} / \mathrm{kg}$; $t$ is the air temperature, ${ }^{\circ} \mathrm{C}$.

The enthalpy fluxes through the interface are determined by the temperature pressure "interface section - vapor-air mixture" and phase transformations.

\section{The essence of the vapor-air desalination method}

As part of the study, a two-factor experiment was carried out that implements a second-order Box-Benkin centrally orthogonal composition plan. The results of an experimental study of the performance of a vapor-type desalination setup were approximated by regression equations according to the experiment planning method. Parameter optimization of PFE is the installation performance. Experiment planning is used to search for 
optimal conditions for the operation of vapor-air type installations, the choice of significant factors [15].

The variable factors are water and air temperatures in the bubbling zone. The factors considered meet two basic requirements for a set of factors: there is no correlation between them, they are compatible. At the same time, each factor is initially considered only at two fixed levels. The upper level for water temperature is $100{ }^{\circ} \mathrm{C}$, the lower level is $70{ }^{\circ} \mathrm{C}$. For processing the results of the experiments and further determining the coefficients of the regression equation, the factors lead to the same scale. This is achieved by coding variables. The experiment plan is written in the form of a planning matrix, in which various combinations of factors are listed in a specific order.

Throughout the study, pressure and air flow were maintained at a constant level. In this case, the total mineralization in the condensate at the outlet of the installation was adopted not more than the required values, that is, not more than $1 \mathrm{~g} / \mathrm{l}$. The relative humidity of the air entering the unit during the experiment is $40 \%$, and the diameter of its inlet pipe is $35 \mathrm{~mm}$. A linear relationship was obtained; the resulting model was inadequate.

To obtain the correct regression equation, a second order plan was drawn up. Second-order plans make it possible to form a response function in the form of a complete quadratic polynomial, which contains a larger number of terms than the incomplete quadratic polynomial, which was formed according to first-order plans, and, therefore, they require a larger number of experiments to be performed. In this regard, the previously formed plan of the PFE is extended to a second-order plan, and a new response function is formed in the form of a full quadratic polynomial, without losing information about previous experiments. In this case, the number of experiments increases, and the factors vary at 3 levels, additional measurements are carried out.

The obtained regression equation of the second order is adequate; accordingly, it can be used to determine the values of the studied quantity without conducting an experiment and giving the factors values that should lie between the lower and upper levels.

According to the results of an experimental study, a second-order regression equation was obtained for the dependence of the productivity of the freshwater installation, $\mathrm{yg} / \mathrm{s}$, on the initial temperature of water and air in the bubbling zone:

$$
\mathrm{y}=\mathrm{b}_{0}-\mathrm{b}_{1} \cdot \mathrm{x}_{1}+\mathrm{b}_{2} \cdot \mathrm{x}_{2}-\mathrm{b}_{12} \cdot \mathrm{x}_{1} \cdot \mathrm{x}_{2}+\mathrm{b}_{11} \cdot \mathrm{x}_{1}^{2}
$$

where $\mathrm{x}_{1}$ is the temperature of heated water in the bubbling zone, ${ }^{\circ} \mathrm{C}, \mathrm{x}_{2}$ is the temperature of the bubbling air, ${ }^{\circ} \mathrm{C}, \mathrm{b} 0, \mathrm{~b} 1, \mathrm{~b} 2, \mathrm{~b} 12, \mathrm{~b} 11$ are the coefficients of the regression equation.

The regression equation yielded the response surface shown in Figure 3.

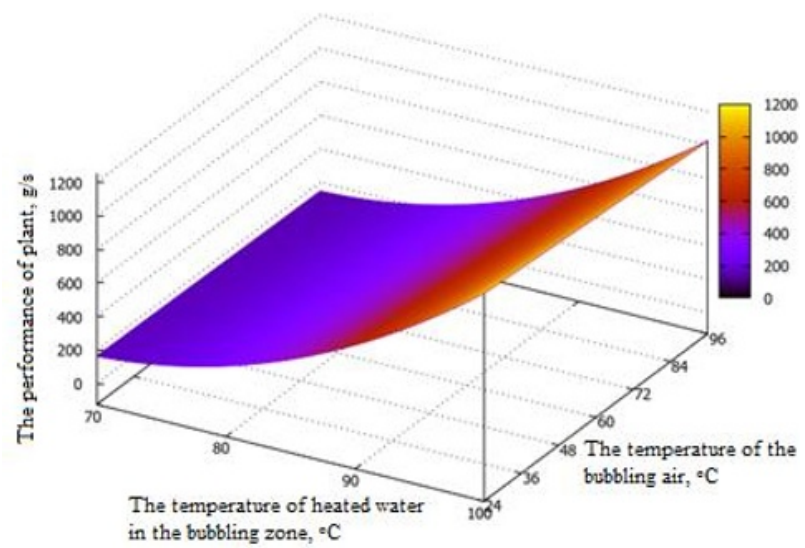

Fig. 3. The response surface of the regression equation.

According to the results of an experimental study, it was found that the key factor determining the efficiency of the installation is the initial temperature of the water in the bubbling zone, and the air temperature has a smaller effect.

\section{Conclusion}

Summarizing all the above, we can conclude that the production of fresh water in devices that implement the vapor-air method is energy efficient. From the analysis of the results obtained, it follows that the initial temperature of the water in the bubbling zone has a key effect on the performance of the installation.

The performance of the pilot setup is several times as high asthe performance of boiling setups (distillers) at equal power consumption.

Thus, for steam-type installations, they are characterized by low equipment cost, ease of operation, the absence of complex seawater preparation, low specific energy consumption, the possibility of obtaining a by-product of crystallized salt.

High energy efficiency with low capital intensity of devices and the quality of the resulting product that meets regulatory requirements, makes the use of devices that implement this method relevant. The results of the work can find their application in systems for the preparation of drinking water of various sizes from household to industrial.

\section{References}

[1] R. Semiat, Desalination: Present and Future.Water International. 25, 54-56 (2000)

[2] R. Semiat, Energy issues in desalination processes. Environmental science \& technology, 228193-201 (2008)

[3] N. Ghaffour, T. Missimer, G. Amy, Technical review and evaluation of the economics of water desalination: Current and future challenges for better water supply sustainability. Desalination, 309197-207 (2013)

[4] V. Kotov, Desalination device with contact heat exchanger. Atomnayaehnergiya. 3142-147 (2016) 
[5] X.H. Ma, Z. Lan, R.F. Wen, B.L. Peng, W. Xu, X. Zhu, X.F. Yan, H. Jiang, Y.C. Wang, P. Yan, Experimental study on the performance of low temperature multi-effect distillation platform for seawater desalination. Gaoxiaohuaxue gong chengxuebao.281210-16 (2014)

[6] K.S. Spiegler, Y.M. El-sayed, The energetics of desalination processes. Desalination.134, 109-28 (2001)

[7] A. Rektor, N. Pap, Z. Kikai, R. Szabi, G. Vatai, E. Bikissylnir, Application of membrane filtration methods for must processing and preservation. Desalination.162 271-7 (2004)

[8] P.S. Sokolov Autonomous desalination devicePatent 2613920 Russia IPC C1 F1/04, opubl.Byul.№9, 5 (2017)

[9] K. Zine-dine, Y. El Hammami, R. Mir, T. Mediouni, S. Armou, Effect of the non-condensable gas type during condensation of water vapor. Thermal science 21, 2457-68 (2017)

[10] E. Peirano, V. Delloume, F. Johnsson, B. Leckner, O. Simonin, Numerical simulation of the fluid dynamics of a freely bubbling fluidized bed: influence of the air supply system.Powder technology. 12269-82 (2000)

[11] J.T. Cieslinski, R. Mosdorf, Gas bubble dynamics - experiment and fractal analysis. International journal of heat and mass transfer.481808-18 (2005)

[12] A. Anwar, T. Faisal, H. Truong, Y. Inoue, F. Takagi, Mass transfer correlation for nonaqueous phase liquid volatilization in porous media. Environmental science and technology. 371277 (2003)

[13] V.I. Prohorov, 1973I-d diagram of moist air for variable pressure 37

[14] V.D. Papaefthimiou, T.C. Zannis, E.D. Rogdakis Thermodynamic study of wet cooling tower performance. International journal of energy research 30, 411-26 (2006)

[15] A.M. Dean, S.M. Lewis, Detection of interactions in experiments on large numbers of factors. Journal of the royal statistical society: series b (statistical methodology).63633-72 (2001) 